\title{
Conhecimento dos educadores dos centros municipais de educação infantil sobre primeiros socorros
}

RESUMO | Objetivo: Compreender o conhecimento dos professores dos Centros de Educação Infantil sobre Primeiros Socorros referentes a crianças de 3 a 5 anos. Métodos: Trata-se de uma pesquisa de caráter exploratório, com abordagem qualitativa, desenvolvida com 18 professores de nove Centros Municipal de Educação Infantil de Divinópolis, localizado no município de Divinópolis, Minas Gerais. Foram realizadas entrevistas individuais no período de julho a dezembro de 2018 , por meio de roteiro semiestruturo, posteriormente os dados foram analisados mediante a Análise de Conteúdo. Resultados: Emergiram três categorias temáticas: O professor do CMEl e sua relação com primeiros socorros: conceitos e suas inseguranças; Primeiros socorros durante acidentes no CMEl: atitudes corretas e incorretas e Educação Infantil: tipos de acidentes e exposições a riscos. Conclusão: É necessário que os professores tenham capacitações periódicas sobre o assunto, assim como os locais de trabalho ofertem material e suporte para os primeiros socorros.

Palavras-chaves: Educação em Saúde; Educação Infantil; Primeiros Socorros; Professores, Crianças.

ABSTRACT | Objective: To understand the knowledge of teachers at the Early Childhood Education Centers on First Aid for children aged 3 to 5 years. Methods: This is an exploratory research, with a qualitative approach, developed with 18 teachers from nine Municipal Centers for Early Childhood Education in Divinópolis, located in the municipality of Divinópolis, Minas Gerais. Individual interviews were carried out from July to December 2018, using a semi-structured script, then the data were analyzed using Content Analysis. Results: Three thematic categories emerged: The CMEl teacher and his relationship with first aid: concepts and their insecurities; First aid during accidents at CMEl: correct and incorrect attitudes and Early Childhood Education: types of accidents and risk exposures. Conclusion: It is necessary that teachers have periodic training on the subject, as well as workplaces offer material and support for first aid.

Keywords: Health Education; Early Childhood Education; First Aid; Teachers, Children.

RESUMEN | Objetivo: Comprender el conocimiento de los maestros en los Centros de Educación Infantil sobre Primeros Auxilios para niños de 3 a 5 años. Métodos: Esta es una investigación exploratoria, con un enfoque cualitativo, desarrollada con 18 maestros de nueve Centros Municipales para la Educación de la Primera Infancia en Divinópolis, ubicada en el municipio de Divinópolis, Minas Gerais. Las entrevistas individuales se llevaron a cabo de julio a diciembre de 2018, utilizando un guión semiestructurado, luego los datos se analizaron mediante el Análisis de contenido. Resultados: surgieron tres categorías temáticas: el maestro CMEl y su relación con los primeros auxilios: conceptos y sus inseguridades; Primeros auxilios durante accidentes en CMEl: actitudes correctas e incorrectas y Educación de la primera infancia: tipos de accidentes y exposiciones al riesgo. Conclusión: es necesario que los maestros tengan capacitación periódica sobre el tema, así como que los lugares de trabajo ofrezcan material y apoyo para primeros auxilios.

Palavras claves: Educación en Salud; Educación Infantil; Primeros Auxilios; Profesores, Niños.

\section{Monaliza Fernandes Souza}

Enfermeira. Graduada em enfermagem pela Universidade do Estado de Minas Gerais, Unidade Divinópolis, Minas Gerais.

ORCID: 0000-0002-13253301

\section{Alessandra Beirigo Divino}

Enfermeira. Graduada em enfermagem pela Universidade do Estado de Minas Gerais, Unidade Divinópolis, Minas Gerais. ORCID: 0000-0002-6102-5530

\section{Débora Aparecida Silva Souza}

Enfermeira. Mestre em Educação em Saúde e Enfermagem. Docente da Universidade do Estado de Minas Gerais, Unidade Divinópolis.

ORCID: 0000-0002-8937-584X

\section{Simone Graziele Silva Cunha}

Enfermeira. Doutoranda na Universidade Federal de Minas Gerais; Docente da Universidade do Estado de Minas Gerais. ORCID: 0000-0002-0445-4822

\section{Camila Souza de Almeida}

Enfermeira. Doutora pela Universidade Federal de Minas Gerais. Docente da Universidade do Estado de Minas Gerais. ORCID: 0000-0002-7032-0945

Recebido em: 30/07/2020

Aprovado em: 19/08/2020

\section{INTRODUÇÃO}

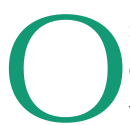
S Primeiros Socorros (PS) envolvem um conjunto de técnicas imediatas que promovem um suporte básico de vida até a chegada do socorro, devendo ser imediato e determina a recuperação das vítimas até o atendimento médico. Os procedimentos de PS podem ser realizados por pessoas comuns ou profissionais da saúde desde que devidamente treinados, pois deverá ser capaz de reconhecer situ- ações que promovam risco a sua vida e a da vítima, necessitando de conhecimento prévio sobre questões de emergências e urgências $^{(1)}$.

Dentre as diversas pessoas que necessitam de treinamento para o atendimento de PS, destaca-se professores que trabaIham com crianças menores de cinco anos idade, pois nessa faixa etária, a criança encontra-se em intenso desenvolvimento físico e motor, com comportamento de caráter exploratório, que a expõe a acidentes, principalmente nos locais em que permanecem maior parte do tempo, como as escolas. $\mathrm{O}$ ambiente escolar por mais que pareça seguro, possui locais de risco, como os parquinhos e pátios ${ }^{(2)}$.

No Brasil, as taxas de morbimortalidade por causas externas têm tomado proporções alarmantes, tornando-se um proble- 
ma de saúde pública, principalmente no que diz respeito a acidentes e violências ocorridos na infância ${ }^{(3)}$. De acordo com a literatura, as escolas e os parques infantis são os principais locais em que ocorrem acidentes, sendo que $40,4 \%$ são quedas e aproximadamente $39 \%$ das lesões relatadas nesses ambientes envolvem mordidas de outras crianças ${ }^{(4)}$.

Dentre os locais de educação no Brasil têm-se os Centros Municipais de Educação Infantil (CMEI), que atendem crianças de 3 a 5 anos que estão se integrando ao sistema de ensino e iniciando a primeira etapa da educação básica. Os $\mathrm{CMEI}$ possuem a finalidade de estabelecer condições para que o aprendizado e o desenvolvimento sejam prazerosos e eficazes, preparando-as para ingressar no Ensino Fundamental ${ }^{(5)}$.

Crianças na faixa etária atendida pelo CMEI são mais suscetíveis a situações de emergência. Essas possuem características comportamentais que a tornam mais propicias a acidentes envolvendo as vias aéreas, maior risco de escoriações e cortes, devido a menor massa corporal e pele fina ${ }^{(6)}$.

Visto que acidentes ocorrem no ambiente escolar, é necessário que os professores conheçam as técnicas de PS. Estudos relatam que muitos acidentes ocorridos nas escolas poderiam ser evitados se os professores identificassem objetos e situações de risco, como cadeiras próximas a janelas. Ainda, os agravos decorrentes desses acidentes seriam evitados com os cuidados corretos e rápidos após o acidente ${ }^{(7,9)}$.

Uma forma de prevenir esses acidentes e proporcionar ao professor uma forma de atender aos PS é através da capacitação. Estudo realizado no país traz que os professores capacitados foram capazes de apontar situações de risco e o como agir em tais circunstâncias. A capacitação leva o indivíduo por meio do senso comum a modificar o conhecimento e incorporar novas experiências e interpretações ${ }^{(6)}$.

Assim, acredita-se que os professores dos CMEI devem ser capacitados em PS, visando a prevenção e o suporte apropriado em caso de acidentes, entretanto, o que se encontra na literatura é o des- preparo desses profissionais para atender as crianças vítimas de acidentes ${ }^{(7,1,11)}$. Desse modo, pergunta-se: "Qual o conhecimento dos professores dos CMEI sobre primeiros socorros relacionados ao atendimento a crianças na primeira infância?". O objetivo do estudo foi compreender o conhecimento dos professores dos CMEl sobre Primeiros Socorros referentes a crianças de 3 a 5 anos.

\section{MÉTODOS}

Trata-se de uma pesquisa de caráter exploratório, com abordagem qualitativa, desenvolvida com 18 professores de nove intuições de educação infantil CMEI, localizado no município de Divinópolis, Minas Gerais.

Divinópolis possui $23 \mathrm{CMEl}$, destarte, a seleção dos locais se deu por sorteio simples aleatório, sendo que inicialmente foram sorteados nove $\mathrm{CMEI}$. Posteriormente, cada diretora da instituição indicou dois professores para as entrevistas, seguindo os seguintes critérios de inclusão: professores que tinham contato direto com crianças de 3-5 anos de idade e no mínimo um ano de docência em educação infantil. Entende-se que esses critérios possibilitaram que as informações coletadas fossem mais fidedignas. O critério de exclusão foi profissionais que se encontravam de férias no momento da coleta de dados. Para realizar o fechamento amostral foi utilizada a saturação dos dados.

Os dados foram coletados por meio de entrevistas com roteiro semiestruturado, iniciando com questões referentes a dados sociais e profissionais e posteriormente com perguntas acerca da compreensão dos professores em relação aos Primeiros Socorros, execução de procedimentos diante de um acidente e indagação sobre os riscos que as crianças e os professores estavam expostos.

A coleta de dados foi realizada por duas discentes de enfermagem do $9^{\circ}$ período, capacitadas previamente pela pesquisadora responsável. O período da coleta de dados foi de agosto a setembro de
2018. Ressalta-se que todas as entrevistas ocorreram no próprio local de trabalho, em sala reservada.

As entrevistas foram gravadas e transcritas na íntegra, com tempo médio de duração de 15 minutos. Todas receberam um código alfanumérico, sendo utilizada a letra $\mathrm{E}$ (Educadores), seguido no número da entrevista. Após a transcrição dos dados na integra, utilizou-se a análise de conteúdo proposta por Bardin ${ }^{(10)}$. Por meio da análise emergiram três categorias temáticas que serão descritas a seguir.

Relata-se que antes do início da coleta de dados com os participantes do estudo foram realizadas três entrevistas pilotos com professores da educação infantil que se encontravam em um município semelhante, com vistas a verificar a assertividade do roteiro de entrevista. Assim, foram realizadas duas mudanças no roteiro de entrevista, primeiro relacionada a ordem das perguntas e posteriormente com a inclusão de perguntas mais diretas sobre primeiros socorros. Todos os dados provenientes da entrevista piloto foram descartados não compondo dessa maneira, o banco de dados do estudo.

O projeto foi aprovado pelo Comitê de Ética de Pesquisa da Universidade do Estado de Minas Gerais UEMG, Unidade Divinópolis com o número do parecer 2.787.634, CAAE: 85013818.0.0000.5115. Os participantes assinaram o Termo de Consentimento Livre e Esclarecido (TCLE).

\section{RESULTADOS}

A pesquisa envolveu 18 professores de nove $\mathrm{CMEI}$, todos os participantes eram do sexo feminino. A faixa etária predominante foi de 40 a 49 anos (50\%). Quanto ao estado civil, 14 (83,33\%) das entrevistadas eram casadas.

Em relação à formação complementar, $14(88,33 \%)$ possuíam pós-graduação. No que concerne à situação profissional, nove (50\%) das professoras trabalham no turno matutino e se encontravam em atividade docente a cerca de 
15 anos. Quanto à quantidade de alunos por professora, está foi de 15,9.

Por meio das entrevistas, foi possível compreender a relação das professoras com os Primeiros Socorros. Emergindo da análise das entrevistas três categoriais temáticas, sendo elas: "O professor do CMEI e sua relação com primeiros socorros: conceitos e suas inseguranças"; "Primeiros socorros durante acidentes no CMEI: atitudes corretas e incorretas" e "Educação Infantil: tipos de acidentes e exposições a riscos".

O professor do CMEI e sua relação com primeiros socorros: conceitos e suas inseguranças

A categoria apresenta os conhecimentos das professoras quanto ao tema e seus anseios em relação à execução do atendimento. Nessa categoria foi nítida a necessidade de maior abordagem do tema na educação infantil.

Quando questionadas sobre o que seria PS, a maioria se expressou com segurança sobre o conceito, demonstrando que compreendiam em teoria o seu significado.

Eu acho que os primeiros socorros são as primeiras providencias. Que a gente tem que tomar em relação a algo que acontece ali no momento, algo inesperado (E2).

São os primeiros cuidados quando acontece um acidente [...]. Aquele socorro imediato (E6).

Bom, são os cuidados necessários na hora que acontece um acidente, o primeiro contato que você vai ter. Como você vai auxiliar nos primeiros momentos, eu acho que é isso (E14).

Algumas professoras compreendem o conceito e frisaram a importância de se ter conhecimento prático, o que proporcionaria a realização dos procedimentos corretos.

Primeiros socorros é aquele momento que a criança [...]. Ela tem algum [...] desenvolve alguma reação no corpo, que pode ser um corpo estranho ou do próprio corpo mesmo, e a gente tem que tentar fazer alguma coisa, dentro do possível, a partir do momento que a gente tem o conhecimento sobre aquilo ali (E5).

É o que eu posso fazer! É como paliativo, até que se leve para o profissional, se for necessário. É o que eu vou tá ajudando, o que puder tá evitando que agrave (E13).

Apesar de demonstrarem certo conhecimento teórico em relação ao tema, quando questionadas quanto aos procedimentos a serem realizados na ocorrência de um acidente, muitas relataram insegurança.

Eu não sei se eu conseguiria, eu acho que diante de um acidente eu não sei se teria controle emocional para isso, principalmente criança [...] (E8).

[...] eu não sou uma pessoa apta para fazer qualquer tipo de Socorro. Não sou...Sinto muito, mas eu não consigo ficar calma! Ter aquela tranquilidade, aquela calma não! Só de me olhar você já vê que estou morrendo de medo (E14).

Percebe-se que o conhecimento teórico existe, porém para a realização dos procedimentos seria necessário prática e capacitação, o que se mostrou insuficiente na presente pesquisa. Os professores tornam-se propensos a realizar atendimento incorreto no momento do acidente.

Primeiros socorros durante acidentes no CMEI: atitudes corretas e incorretas

Nos CMEI, os acidentes ocorrem principalmente nos momentos que as crianças estão em atividades coletivas, nos pátios e parquinhos. Essa categoria relata as atitudes tomadas pelos professores quando ocorre algum tipo de acidente.

As falas a seguir demonstram atitudes corretas tomadas durante os acidentes.
[...] Quando acontece da criança bater com a cabeça, tem a observação da pupila, a gente tem que observar se houve a dilatação, sonolência, vômito, dor de cabeça e acionar também a família ou o SAMU se for necessário, se houver um desmaio alguma coisa assim (E5).

Uai, não sei nem se é isso mesmo, né? Mas a gente observa para ver se a criança tá ficando mole, sonolenta, se não teve corte, porque se teve corte, a gente tem que encaminhar para o serviço médico (E12).

As atitudes incorretas na tentativa de prestar algum tipo de socorro foram as mais relatadas entre as professoras. Mesmo sabendo que o procedimento é incorreto, elas o realizam, por ser o único conhecimento disponível no momento.

Ela estava comendo carne, sabe? Foi carne de panela, aí ela engasgou, na verdade eu até tentei fazer atrás (gesto apontando para as costas), pelas costas, não consegui, não tive resultado, aí eu enfiei o dedo, eu sei que não pode, que não é o certo, mas o que deu certo foi enfiar o dedo e puxar (tirar o pedaço de carne com os dedos) (E1).

Eu sigo o meu instinto mesmo! Se é sério eu vejo. Se acontecer de eu ver que precisa de dar ponto, eu não penso duas vezes, eu ligo para mãe, não conseguiu não, já põe no carro e leva para o hospital, mesmo correndo algum tipo de risco. A gente trata igual filho (E17).

A primeira coisa foi pegar a criança, porque notei que ela estava sentada e começou a balançar a mãozinha e eu chamei e ela não correspondeu, imediatamente eu peguei ela no colo e ela já foi virando o corpo, eu vi que virou o olho, baixou a cabecinha e começou a espumar a boca e ficou 
roxa. Aí, eu desci com ela pela a rampa, já levei ela para o banheiro, virei ela para esquerda e joguei água no rostinho dela (E18).

As atitudes mesmo que incorretas são percebidas pelos professores como necessárias para evitar agravos. Percebe-se que os profissionais desejam prestar os cuidados, mas falta a eles uma capacitação adequada. Apenas uma participante (E17), relatou que não seria da competência de ela prestar o primeiro atendimento.

Olha, eu acho que esse assunto, ele realmente é muito sério e eu penso assim, que em cada escola deveria ter uma equipe, não sei se é uma equipe, mas pelo menos um enfermeiro (E17).

Mesmo nas ações realizadas corretamente nota-se o receio das professoras na prática de PS. Identifica-se que elas não sabem a ação correta, agindo no ímpeto de socorrer as crianças e evitar algum tipo de agravamento da situação.

Educação Infantil: tipos de acidentes e exposições a riscos

Entre as situações em que as crianças estão em maior exposição ao risco destaca-se o horário que elas estão fora da sala de aula, no pátio e/ou no parquinho em que o controle por parte dos professores é menor.

No parquinho, no pátio... São os lugares onde as crianças brincam livremente, então acontece muitas vezes deles trombarem com outra criança (E2).

[...] Acontece umas coisas inevitáveis! No balanço, de bater o balanço na cabeça de outra criança. Mas assim, nosso CMEI, esse ano e nos anos anteriores, não teve muito acidente, é esporádico, acontece de cair e bater a boca e das crianças darem umas cabeçadas umas nas outras (E4).
Eu acho que são vários os momentos, por exemplo, na entrada e na saída (das aulas) e no horário do Recreio, que é o momento de recreação. Eu acho que são os momentos mais propícios para os acidentes acontecerem (E16).

A infraestrutura do CMEI pode facilitar a ocorrência de acidentes mais graves, como relatado na fala abaixo:

[...] uma criança bateu na porta da sala (ela cortou o braço, um corte profundo devido ao vidro que caiu no braço dela), e as portas daqui tem vidro, eu falei que eu nunca vi uma escola voltada para educação infantil, porque aqui é pró-infância, com tanto vidro (E9).

Muitos dos CMEI possuem infraestrutura adaptada, com portas de vidros, escadas sem proteção e rampas íngremes, o que pode proporcionar acidentes. Mas, mesmo que os ambientes mais propensos a acidentes sejam ao ar livre, as professoras frisam que em qualquer local há risco para a faixa etária que atendem, tornando-as vigilantes constantes.

Eu acho que é a qualquer momento que a criança está exposta. Em qualquer lugar, em quaisquer momentos, não é robô que fica quieto. Sempre está andando, está brincando, então eu acho que em qualquer lugar ou a qualquer momento a criança está exposta (a acidentes) (E10).

As professoras também relataram quais os principais tipos de acidentes que ocorrem no local. Tendo destaque as quedas que acontecem com as crianças nos momentos de brincadeiras, como é apresentado abaixo.

Corre, aí tromba. Bate à cabeça, alguma coisa assim.... É em algum brinquedo, no escorrega e cai. O balanço volta em cima da criança [...] (E3).

Trombada! Porque eles estão na fase de correr muito, então no recreio eles acabam trombando um no outro e no parquinho pode acontecer de passar na frente do balanço, são essas questões (E12).

Além das crianças, os professores também estão expostos a riscos físicos e biológicos, como é relatado pela participante E14 quando questionada sobre como realizam a limpeza de locais em que ocorrem acidentes com as crianças.

A gente pegou o papel higiênico e estava sem o álcool, usei foi o veja mesmo? [...] (E14).

Apesar da maioria dos professores desconhecerem ou não perceberem a importância do uso do Equipamento de proteção individual, apenas uma participante E16, relata a importância do uso das luvas de procedimento e outros materiais, como é expresso na fala abaixo.

[...] no primeiro momento, você lava o ferimento usando luvas para não ter contato direto com o sangue. Lavar o ferimento com água e sabão, colocar gazinhas para poder estancar, que é um material limpo e higienizado para não ter algum outro problema com a criança (E16).

O próprio ambiente escolar tem sua parcela de influência nos acidentes que acontecem no $\mathrm{CMEI}$, pois, sua infraestrutura traz riscos para as crianças, uma vez que os parquinhos possuem brinquedos que propiciam a queda, como por exemplo, gangorras, balanços e escorregador. Já para os professores, os riscos estão presentes no momento do atendimento, uma vez que, ao socorrer a criança agem da maneira que julgam adequada, ficando exposto a fluidos e quedas no momento da locomoção. 


\section{DISCUSSÃO}

O presente estudo demonstra que a prática dos PS ainda é de difícil manejo para os profissionais da educação infantil em vista dos relatos de despreparo. Observa-se nas falas que existe uma preocupação quanto ao tema, embora os professores demonstrem conhecerem o conceito de PS, a prática é inadequada e ineficaz pois não há treinamento e capacitação. Esse treinamento quando realizado é feito pelos profissionais de saúde da Atenção Primária em Saúde, principalmente pelos enfermeiros(6). $\mathrm{Na}$ maioria dos casos as instituições de ensino não promovem por si mesmos esses treinamentos.

Outro fator revelado pelos discursos dos professores é o despreparo, dentre os motivos se tem a escassez do conteúdo nas grades curriculares dos cursos de humanas, como a pedagogia que tem seu conteúdo direcionado para o desenvolvimento educacional e a psicomotricidade da criança. Não se atentando para possíveis acidentes, resultando na falta de conhecimento adequado sobre o assunto. Nesse sentido, torna-se responsabilidade da professora realizar cursos sobre o assunto e do local de trabalho ofertar capacitações sobre a temática ${ }^{(12-13)}$.

Os resultados deste estudo corroboram com um trabalho realizado no Município de Cruzeiro em São Paulo, em que os pesquisadores demonstraram que as ações realizadas no momento dos PS pelos professores são inadequadas, confirmando uma falta de prática e conhecimento teórico $^{(7)}$. Essa realidade não é apenas nacional, estudo conduzido no Egito, aponta que aproximadamente $60 \%$ dos professores não possuem conhecimento sobre PS, ademais o estudo revela o despreparo dos professores, criando-se um choque em relação à teoria e conhecimento prático ${ }^{(14)}$.

Os conhecimentos demonstrados pelas professoras em relação a alguns procedimentos do suporte básico de vida são derivados do instinto de proteção. Pode-se inferir que o instinto é proveniente da experiência materna, colaborando para execução de determinados procedimentos de forma correta. Além, dos conhecimentos empíricos aprendidos por meio da observação de outros profissionais e da mídia ${ }^{(15)}$. Os procedimentos realizados de forma empírica podem colocar em risco a vida das crianças e até mesmo das professoras, como relatado pelas mesmas que não fazem o uso de EPIs durante os atendimentos, ficando em contato direto com fluidos corporais e até mesmo risco de quedas.

Quando se busca uma capacitação dos profissionais e o tipo de conhecimento que os mesmos devem adquirir para o planejamento dos PS, deve-se pensar em que tipos de acidentes são os mais comuns na faixa etária em que se está trabalhando. No presente estudo foram os acidentes que envolvem quedas, cortes, convulsões, fratura, desmaios, trombadas que envolvem colisão de cabeças e sangramento nasal. Esses acidentes também são os mais mencionados pela literatura ${ }^{(8,16)}$. Com base nesses conhecimentos seria possível a promoção de capacitações mais específicas e voltadas para os riscos enfrentados pelas professoras e alunos.

O conhecimento dos principais tipos de acidente também pode auxiliar na estruturação dos espaços físicos, pois o tipo de construção e materiais disponíveis no ambiente escolar atua de forma direta nas ocorrências dos acidentes ${ }^{(9,13,15)}$. Neste estudo encontrou-se que a maioria dos casos geradores de urgência ocorrem, principalmente, nos horários de recreação, momento que a criança está livre para realizar suas atividades e brincadeiras fora da sala de aula.

A infraestrutura física do ambiente escolar deveria ser padronizada, o Ministério da Educação (MEC), por meio do Fundo Nacional de Desenvolvimento da Educação (FNDE), que está dentro do Programa Nacional de Reestruturação e Aquisição de Equipamentos para a Rede Escolar Pública de Educação Infantil (Pro infância) possui, manuais norteadores para a construção de um ambiente escolar saudável e de qualidade, que nem sempre são seguidos ou fiscalizados ${ }^{(16)}$.

O principal acidente apontado pelas professoras é a queda, seguida das lesões provenientes da batida de cabeça, desmaio, corte e sangramento, confirmando o que literatura sobre essa temática traz ${ }^{(4)}$. A criança de 3-5 anos de idade entra em um período no qual sua psicomotricidade começa a se desenvolver, tornando-a mais exposta a quedas e cortes no ambiente escolar ${ }^{\text {(17-18-19). }}$

Muitas professoras ressaltaram a importância da capacitação para um melhor cuidado com as crianças, mas não citam como essa capacitação seria importante para sua própria segurança, pois durante os PS elas ficam expostas a fluidos corporais e quedas. No momento do acidente, as professoras não se preocupam em utilizar material para proteção ou percebem que estão expostas a quedas ${ }^{(20)}$.

Uma forma de aperfeiçoar o conhecimento das professoras é por meio da educação em saúde que deveria ser em parte responsabilidade do município, com a busca de parceria e trabalho em rede, entre a educação e a saúde. Entende-se que a educação em saúde é um instrumento para promoção da qualidade de vida, relacionando os saberes populares com os científicos, fazendo com que esses profissionais possam incorporar os conhecimentos restritos ao meio acadêmico a sua prática diária $^{(21)}$.

Pesquisa realizada em São Paulo, demonstra que capacitação em PS, por meio da educação em saúde é positivo, principalmente na área da educação infantil. A pesquisa realizou um pré-teste antes da capacitação e um pós-teste após a capacitação, com docentes de uma escola, que demonstrou o conhecimento deficiente antes da capacitação e um conhecimento mais aprimorado após ${ }^{(6)}$. Uma revisão bibliográfica também relata a importância e eficácia da educação em saúde sobre o tema ${ }^{(21)}$. Em se tratando de PS, é de grande valia, já que se tem o desconhecimento por parte da população sobre o assunto, podendo levar a proce- 
dimentos desnecessários ou que agravam a situação da vítima ${ }^{(8)}$.

Pensando na necessidade do vínculo da saúde com a educação foi criado o programa Saúde na escola, que é a parceria da Atenção Primária em Saúde com as escolas $^{(22)}$, sendo mais uma oportunidade da realização de educação em saúde com os professores. Nesse contexto, o enfermeiro é o articulador da rede de saúde, podendo promover capacitações e parcerias com as escolas $^{(23)}$, ademais, é o profissional de saúde que está na linha de frente do cuidado, tendo em sua formação as ferramentas para realizar a educação em saúde ${ }^{(22)}$.

Em relação às limitações do estudo é importante destacar que as entrevistas aconteceram no horário de intervalo dos professores, o que acarretou algumas interrupções durante as entrevistas. Teve-se também dificuldade em se encontrar local privativo nos $\mathrm{CMEI}$, mas se preservou a privacidade e anonimato de todas as entrevistas.

\section{CONCLUSÃO}

O presente trabalho demonstrou que os professores da educação infantil entrevistados não possuem conhecimento suficiente sobre PS para aplicação em suas práticas diárias com as crianças dos CMEI. Essa lacuna práticateórica coloca em risco não apenas as crianças, mas os próprios professores que se expõe a riscos de quedas e a fluidos corporais.

Apesar do reconhecimento da importância do tema, os profissionais não são capacitados pelos responsáveis dos CMEls, além de não haver parcerias entre Atenção Primária em Saúde e Educação. Assim, diante ao exposto, nota-se que é urgente a necessidade de capacitações no que tange a temática de PS. Sendo que o profissional enfermeiro que atua na Atenção Primária em saúde poderia ser um importante articulador entre saúde e educação, por estar na linha de frente do cuidado e ter em sua formação ferramentas para educação em saúde.

\section{Referências}

1. Karren JK, Hafen BQ, Limmer D, Mistovich JJ. Primeiros socorros para estudantes. $10^{\circ}$. ed. Barueri-SP, Brasil: Editora Manole; 2013.

2. Brasil. Ministério da Saúde. Cadernos de atenção básica saúde da criança: crescimento e desenvolvimento. Brasília-DF. 2012.

3. Lima LL, Neves JR. Brigada estudantil de prevenção de acidente primeiros socorros em Palmas (TO). Rev. bras. educ. méd. 2016; 40 (2): 310-13. http:// dx.doi.org/10.1590/1981-52712015v40n2e02512014.

4.Li F, Sheng X, Zhang J, Fan J, Shen Conhecimento pediátrico primeiros socorros e atitudes entre o pessoal nas pré-escolas, China. BMC Pediatr. (online). 2012; 12(121): 1-8. https://doi.org/10.1186/1471-2431-14-209

5. Nascimento FC. CMEIS: política pública voltada ao "assistencialismo" ou oportunidade para a socialização e desenvolvimento infantil. Publ. UEPG Humanit. Sci., Linguist., Lett. Arts. 2012; 20 (1): 43-54. Doi: http://dx.doi. org/10.5212/publ.humanas.v20i1.3659.

6. Calandrim, LF, Santos AB, Oliveira LR, Massaro LG, Vedovato CA, Boaventura $A B$. Primeiros Socorros na Escola: Treinamento de Professores e Funcionários. Rev Rene (Online). 2017; 18 (3): 292-99. Doi: https://doi. org/10.15253/2175-6783.2017000300002.

7. Oliveira, MA, Silva CG, Toledo EM. O Conhecimento em Pronto-Socorrismo de Professores da Rede Municipal de Ensino do Ciclo I de Cruzeiro-SP. ECCOM. 2013; 4 (7): 39-48.

8. Fioruc BE, Molina AC, Vitti WJ, Lima, SAM. Educação em saúde: abordando primeiros socorros em escolas públicas no interior de São Paulo. Rev. eletrônica enferm(online). 2008; 10 (3): 695-705. Doi: https://doi.org/10.5216/ ree.v10.46619

9. Galindo NMN, Caetano JA, Barros LM, Silva TM, Vasconcelos EMR. Primeiros socorros na escola: construção e validação de cartilha educativa para professores. Acta Paul Enferm. (online). 2017; 30 (1): 87-93. Doi: http://dx. doi.org/10.1590/1982-0194201700013.

10. Bardin L. Análise de conteúdo. $3^{\circ}$. ed. São Paulo, Brasil: Edições 70; 2016. 11. Silva LGS, Costa JB, Furtado LGS, Tavares JB, Costa JLD. Primeiros socorros e prevenção de acidentes no ambiente escolar: intervenção em unidade de ensino. Enferm. Foco(brasiilia). 2017; 8 (3): 25-9. Doi: https://doi. org/10.21675/2357-707X.2017.v8.n3.893.

12. Silvani CB, Gomes GC, Sousa LD, Souza JL. Prevenção de acidentes em uma instituição de educação infantil: conhecimento dos cuidadores. Rev. Enferm UERJ. 2008; 16 (2): 200-5.

13. Ganfure G, Ameya G, Tamirat A, Lencha B, Bikila D. et al. First aid knowledge, attitude, practice, and associated factors among kindergarten teachers of Lideta sub-city Addis Ababa, Ethiopia. PLos ONE. 2018; 13 (3): 1-8. Doi: https://doi.org/10.1371/journal.pone.0194263 .

14. Oliveira LJP, Bruno KF, Mohn CRN, Ramos ATN. Conhecimento dos profissionais de Centros Municipais de Educação infantis (CMEIS) de Goiânia sobre traumatismo dentário: base para promoção de saúde. ROBRAC (online). 2016; 25 (74): 130-42.

15. Galindo NMN, Carvalho GCN, Castro RCMB, Caetano JA, Santos ECB, Silva TM, et al. Vivências de professores acerca dos primeiros socorros na escola. Rev. bras. enferm. 2018; 7 (4): 1775-82. Doi: https://doi. org/10.1590/0034-7167-2017-0715.

16. Brasil. Ministério da Educação. Resolução /CD/FNDE $n^{\circ} 6$ de 24 de abril de 2007. Estabelece as orientações e diretrizes para execução e assistência financeira suplementar ao Programa Nacional de Reestruturação e Aquisição de Equipamentos para a Rede Escolar Pública de Educação Infantil - PROINFÂNCIA. 2007.

17. Li F, Sheng X, Zhang J, Fan J, Shen Conhecimento pediátrico primeiros socorros e atitudes entre o pessoal nas pré-escolas, China. BMC Pediatr (online). 2012; 12(121): 1-8. Doi: https://doi.org/10.1186/1471-2431-14-209. 18. Pereira KC, Paulino JR, Saltarelli RMF, Carvalho AMP, Santos RB, Silveira $\mathrm{TVL}$, et al. A construção de conhecimentos sobre prevenção de acidentes e primeiros socorros por parte do público leigo. Rev. enferm. Cent.-Oeste Min. 2015; 5 (1): 1478-84. Doi: http://dx.doi.org/10.19175/recom.v0i0.456.

19. Kumar S, Kulkarnl P, Srinivas N, Prakash B, Hugara S, Ashok NC.Perception and practices regarding first-aid among school teachers.Mysore. Natl J Community Med. 2013; 4(2), 349-35. Doi: http://dx.doi.org/10.15253/21756783.2017000300002 .

20. Coelho, JPSL. Ensino de primeiros socorros nas escolas e sua eficácia. Revista Científica do ITPAC. 2015; 8 (1): 1-4.

21. Silva DP, Nunes JBB, Moreira RTF, Costa LC. Primeiros socorros: objeto de educação em saúde para professores. Rev. enferm. UFPE on line. 2018; 12 (5): 1444-53. Doi: https://doi.org/10.5205/1981-8963-v12i5a23459 2p1444-1453-2018.

22. Lanzoni GMM, Meireles BHS, Cummings G. Práticas de liderança do enfermeiro na atenção básica à saúde: uma teoria fundamentada nos dados. Texto context enferm. 2016; 25(4):e4190015.

23. Magnée T, Beurs DP, Boxem R, de Bakker DH, Verhaak PF. Potencial for substitution of mental health care towards family practices: an observational study. BMC Fam Pract. 2017; 18(1): e10. Pubmed PMID: 28143421. 